\title{
Strategies of Colour, Mysticism of Form in Anita Desai's In Custody
}

Anne Le Guellec

\section{(2) OpenEdition \\ 1 Journals}

Electronic version

URL: https://journals.openedition.org/ces/8424

DOI: $10.4000 /$ ces. 8424

ISSN: 2534-6695

Publisher

SEPC (Société d'études des pays du Commonwealth)

\section{Printed version}

Date of publication: 1 April 2010

Number of pages: $75-86$

ISSN: 2270-0633

\section{Electronic reference}

Anne Le Guellec, "Strategies of Colour, Mysticism of Form in Anita Desai's In Custody", Commonwealth Essays and Studies [Online], 32.2 | 2010, Online since 18 December 2021, connection on 31 January 2022. URL: http://journals.openedition.org/ces/8424 ; DOI: https://doi.org/10.4000/ces.8424

\section{(c) $($ †) $\ominus$}

Commonwealth Essays and Studies is licensed under a Licence Creative Commons Attribution - Pas d'Utilisation Commerciale - Pas de Modification 4.0 International. 


\section{Strategies of colour, mysticism of form in Anita Desai's In Custody}

The line of argument of this essay owes much to Anita Desai's criticism of the colours used in the film adaptation of her novel and her likening of her own approach to the school of New Realism. The essay tries to show how the ethical and aesthetic perspectives are inseparable by studying the way references to colour serve to generate meaning in this dark postcolonial novel. A discussion of the ending and another crucial scene in black and white purports to show that Desai remains somewhat ambivalent towards realism however, being also strongly attracted to a more formalist definition of art.

Tn 1984, Anita Desai published In Custody, a novel which relates the tragicomic misadventures of Deven Sharma, a mediocre university lecturer of Hindi and failed poet, as he attempts to restore an old Urdu poet to his former glory in the uncongenial context of Post-Partition India, dominated by the American and Japanese models of prosperity. The novel marked a turning point in Desai's career, as it was the first to be centred on a male character. The author explained this change of focus as a need to "open doors and widen the canvas" (Costa), and the critics generally hailed it as a positive move towards realism. In 1993, Ismail Merchant, who was himself from an Urdu-speaking Indian background and who felt very concerned by the decline of the cultural aura of Urdu in India, adapted the novel for his first feature film as film director. Anita Desai co-authored the screenplay. The film obtained National Awards from the Government of India for Best Picture, Best Actor, Best Costume and Best Production Design. Yet Desai admitted that she was "shocked" when she first saw the adaptation of the vision she had expressed in her novel:

In my imagination it was all very grey, very dark and dirty, and I just couldn't believe my eyes when I saw it in gorgeous Technicolor, and everyone beautifully dressed, looking very handsome... [...] It's his vision of the book. He is very happy with it. It is not my vision: I would have preferred it in black and white, more in the school of New Realism. (Costa)

Desai's rejection of Technicolor, and her reference to the black and white of New Realism as visual metaphor of her own writing technique, are what inspired this paper which will focus on the use of colour from an ethical as well as aesthetic perspective. One of the concerns here will be to situate the prevailing greyness of the novel between a militant verism and a more abstract modernist symbolism. Another correlated concern will be to classify and interpret the references to residual colour, highlighting its aggressive and repulsive connotations, which put it completely at odds with the kind of vitalist exoticism usually associated with 
representations of India. This will open out onto an exploration of the more tentative references to black and white, especially regarding calligraphy and geometric abstraction, so as to try and determine whether it may be read as an attempt, or perhaps a temptation, to offer a formalist answer to a nauseous postcolonial reality.

The many problems posed by the film adaptation of literary texts are well known, since the classics have become increasingly convenient substitutes for new, groundbreaking scenarios. The adaptation of In Custody could constitute a case in point, not so much concerning the faithfulness to the story and dialogues as the fidelity to the setting and costumes. For instance, this is how chapter 3 opens, with a description of an Old Delhi bazaar into which Deven ventures for the first time to seek out the poet he means to interview: "If it had not been for the colour and the noise, Chandni Chowk might have been a bazaar encountered in a nightmare." (31). Here colour helps to anchor the description in the "real" which is perceived as positive by contrast with the nightmarish maze of lanes, the heat and the crowds. Nevertheless, this reality is the colour of the "poisongreen and red sherbets" which the main character "contemptuously" refuses, and of the "lurid" Japanese nylon saris which remind him of "gaudy" prostitutes. This vision is indeed very different from the one propounded by Merchant, who chose to shoot the film in Bhopal instead of Delhi: "Delhi is too crowded. We wanted space and serenity and visual beauty." (Meer) The priority granted to aestheticism over fidelity to the source imaginary world is put into relief by the astonishing introduction of beds of blooming roses in the dreary courtyard of the poet's house, and the no less amazing "colorization" of a scene which is cut short in the novel: Deven runs away just as the poet's two wives (one in brown and the other in a black and silver getup) are about to jump at each other's throats. In the film, we actually see them grapple with each other, respectively dressed in truly glorious Technicolor blue and red. Desai's regretful wish that her novel might have been shot in black and white can therefore be understood first and foremost in terms of an "ethical" divergence between a commercial film industry (although they are "independent", the films produced by the Merchant and Ivory company are famous for their opulent sets and a marked preference for star actors), and the politically committed films of the Indian New Realism movement of which Satyajit Ray is, of course, one of the best known representatives in the West. The question, therefore, will be to determine in what sense Desai's writing is metaphorically equivalent to New Realism's predilection for black and white.

In interviews, Desai begs to differ from the critics who have described her vision as tragic or nostalgic, and claims rather, for her novels in general, an uncompromising brand of realism: "I would prefer to think that the books face the truth and don't create illusions." (Costa). The butt of her "realist" criticism in In Custody is primarily the sterility and dreary mediocrity of contemporary India, where any vision of the future seems impossible. This is partly due to India's neo-colonial subservient acceptance of the American and Japanese models 
of technological progress and consumerist prosperity. Yet the novel also shows how the legacy of the Partition polarized communal allegiances, the Muslim minority revengefully confiscating the tradition of Urdu poetry, while the Hindu Establishment systematically underfunded the defence of Urdu culture and even actively sought to obliterate the Muslim past. In her novel, Desai underscores the absence of any sense of national unity based on a common history or territory, and on the break-up of identification references, whether they be cultural (these being decentred towards Pakistan or the Middle-East for the Muslims since the Partition, or even towards the West, because of colonial acculturation), or economic, the United States being perceived as the fabulous hub of world economic development.

In Mirpore, the fictitious town which is emblematic of the small towns of India, the absence of any national cohesion and the lack of knowledge of, or even interest in, a common history, is manifest in the institutional and popular neglect of the local historical monuments (12-13) and of High Cultural traditions. Deprivation of a sense of national destiny also means an absence of political vision and of a truly constructive economic activity. This general dearth coincides in Mirpore with a kind of geographic fatality, the drought being a prevailing feature of the region. Moreover, the sterile mediocrity of the small town is not merely borne, it appears to be fully assumed ("Mirpore spared no effort to give an impression of total aridity" 14). This complacent and stubborn negativity is rendered constantly visible and palpable through the omnipresent dust, which throws a homogenizing pall over everything. Beyond the metaphorical parallel that can be established between Anita Desai's writing ethic and the aesthetics of New Realism, it is now useful to explore how colour is actually made to work and acquire meaning in the novel; how it is used, in particular, to portray the mediocrity of Mirpore, which does designate any particular town, but, as has been said, stands for all the provincial towns of India. Because dust is such a dominant feature of the town, greyness prevails. It even has the upper hand over the dramatic brightness of the blood spilt when the yearly Shi' ite commemorations of Hussain's martyrdom coincide with the colourful Hindu festival of Holi: "Knives flashed, batons flailed and blood ran. For a while tension was high [...]. Then the dust of Mirpore rose and swirled and buried everything in sight again; the citizens of Mirpore returned to their daily struggle to breathe" (15). Since the whole plot unfolds during the particularly dry season between March and August, images of sterility, of drought and of death are prevalent in the descriptions of the plain where Mirpore is set. Reality, as seen by Deven through the bus window on his trips to and from Delhi, appears as a dusty whitish-grey wasteland, drearily enhanced by "the scattered carcasses of cattle that littered the landscape and yet rendered it more bleak and more bare under the empty sky." (21) Although Desai does not actually quote from T. S. Eliot's Waste Land here, as she did in Clear Light of Day, the existential desert in which Deven tries to find meaning to his life smacks of modernist pessimism, trapped between the collapse of traditional values and a dehumanising modernity. 
Yet Desai's greyness never dematerialises enough to completely resemble the abstract metaphysical deserts. On the contrary, it often retains the persistent, disgusting texture of a reality that is closer to the kitchen sink realism of the sixties than to Eliot's high modernism. Moreover, in Desai's novel too, the protagonist's Romantic illusions are dissolved in the dreary mediocrity of provincial life:

Dawn was breaking at the end of the road as Deven rattled homewards in the bus. At least, that was how the poets described it, he thought bitterly as he looked through the dust filming the windowpane at the sooty darkness lightening to grey as if the soot and smuts were being dissolved in dishwater. [...] Dawn and poetry, he thought as he spat out a shred of tobacco from his mouth that felt painfully unclean at this hour of morning, all that was simply not real, not true. [...] Any reality was preferable, he told himself, even if it was the smeared window of a country bus bumping along the rutted road homewards. (62)

In this passage, the description dwells rather heavy-handedly on the filth which colours the bitterness and despair of the disillusioned character. Elsewhere in the novel, dirt corrupts further into mould, and disillusion into physical decrepitude:

The tedium [of his wife's sulking] settled upon him like a grey, crumbling mildew. He felt aged and mouldy. He was sure his teeth had loosened in the night, that his hair would come out in handfuls if he tugged it. That was what she might well do, he feared, to teach him not to venture out of the familiar, safe dustbin of their world [...] Now he would sink back on to the dustheap like a crust thrown away, and moulder. (66)

In this extract, the metaphor of mould which stands for Deven's weary resignation to the tedium of his life is initially rather conventional. However, it soon loses its conventional transparency to thicken with the expansion of the paradigm of refuse and decay, pushing neutral realism towards a kind of Beckettian expressionist excess.

Of course, it may seem paradoxical to think in terms of expressionist greyness, insofar as grey is often perceived as a non-colour, used merely to signify the absence of "positive" colour, as well as the absence of meaningful contrast. What role, then, and what significance can we confer on the residual colour in In Custody? Is it meant to lighten the otherwise unrelieved ideological greyness of Desai's vision in the novel, or is it merely a more garish shade of life's depressing negativity? Since the action of the novel takes place during the driest period of the year, the main colour that works along with grey to signify mediocrity and failure is, of course, yellow: the dust is yellow, as is the overheated sky, the parched vegetation, the walls of the college and of Deven's house. The sticky balls of candy (about the only product manufactured in Mirpore) are also yellow, as are teeth, bilious faces, and eyes. Even Nur's beard is compared to "rather old and yellowed stuffing" (81), and the puddle of vomit Deven is made to clean up with sheets of paper that may have been inscribed with the poet's unpublished poems, is, 
of course, yellow (59). Yellow, too, are the envelopes of the telegram and the postcards which summon Deven back to Delhi for further humiliations; and so is the greasy bill for the renting of the room in which he vainly tried to record Nur's poetry (205). As a variation on this drab yellow, the colour gold tends to be associated with capped teeth, vulgar gold chains, cufflinks (notably on a brothel bouncer, or the flashy embroideries on gaudy saris. Yellow being here but a variation on the prevalent greyness, one might expect other colours, such as red, conventionally more dramatic, to stand out against such an unprepossessing background.

Red, however, is not often mentioned in the novel, even if most of the historical buildings are built in red sandstone. As we have seen before, the dramatic vision of the blood spilt during conflicts between Hindus and Muslims is only briefly alluded to, and quickly covered over by a pall of grey dust. In the same way, when Deven's bus hits a stray dog, the stress is laid on the sudden cloud of yellow dust, that rises as the bus violently swerves, and on the passengers' consequent choking. The dog is further obscured from view by a flock of crows, thus blocking Deven's interpretation of the incident as an omen of his own impending doom: "He turned and peered out of the window to see if the dog lay on the road, broken, bleeding, or dead. He saw a flock of crows alight on the yellow grass that grew beside the ditch, their wings flickering across the view like agitated eyelashes." ( 20) In the face of dramatic events, the narratorial gaze is very discreet. However, the description is much more detailed when dealing with an anatomy of ordinary greed. For instance, mouths are quite often seen greedily stuffed with paan, the red betel-stained teeth enhancing the ruthlessness of a character. Murad, whose breath is said to be "foul" (10), always behaves in a particularly rapacious and parasitic manner, advertised by his compulsive chewing and his red teeth. Along with rouge, betel is also an important feature of the description of the recital given by Imtiaz Begum, Nur's ambitious second wife. Aggressively made-up, as if to show her audience that she has definitively taken over from her mentor, Imtiaz smiles a terrifying smile while accepting her favourite treat: "Someone brought a silver box of betel nuts and leaves - the smile Imtiaz Begum gave was as sudden and swift as if scissors had cut it through her face, snip-snap, and the teeth were stained red besides." (83). In this passage, Imtiaz, with her brightly painted face, lips, finger-and toenails, appears as a scissors-wielding, castrating kind of Durgafigure. As far as make-up is concerned, red, like black, does not embellish; rather, as in the case of the folds of "horrendously dyed black hair" which frame Imtiaz's face but also fall in limp coils at the foot of her bed, or in the case of the khol which sets off the brothel owner's eyes, black advertises a monstrosity which is both threatening and sickly: "The tall woman with the pock-marked face, holding a pink veil across it, glared through two huge rims of kohl. [...] She did not shut the door after them but stood glaring through the two baleful kohl-rims of her eyes at them." $(187,88)$ 
It might be expected that, in a world so overcome with drought, so lacking in freshness and vitality, occurrences of green and blue would bring some relief. The colour green does play this role very fleetingly in an unexpectedly harmonious scene bringing together Deven and his son. Having decided he will reconcile himself to his mediocre professional and family life in Mirpore, Deven takes his small son for a walk and suddenly experiences a moment of unexpected loving complicity with him. The emblem of this brief moment is the feather of a green parrot:

One brillant feather of spring green fluttered down through the air and fell at their feet in the grey clay. Deven bent to pick it up and presented it to his son who stuck it behind his ear [...]. Yes, it was the climax of that brief halcyon passage. It was as if the evening star shone through at that moment, casting a small pale illumination upon Deven's flattened grey world. (74)

It is interesting to note that the feathers of the same parrot, just a page before, were described as "acid green against the pale yellow" of the sky, as the bird circled above the pair. The fact that the same colour acquires a new meaning once it is set off by the unrelieved "grey" of Deven's "flattened" world might suggest that the positive and negative connotations of colour only depend on the main character's protagonist's changeable state of mind. However, as Marta Dvorak points out in her book on In Custody (2008), the surprising consistency with which green is associated with unpleasant things does suggest that an "objective", albeit sometimes almost grotesque correspondence, is being established by the narrator between shades of green and septic, chemical or artificial things, or between green and negative emotions. Indeed, not only are Mirpore's tanks of stagnant water green, but so is the "chemically lush", "fertilizer-fed" vegetation around the Veterinary and Agricultural College $(17,64)$. The unwelcome nylon shirt given to Deven by his in-laws is also green, and it crackles with static electricity (18). The dirty thumbnail of a milkman on the bus and another passenger's eye-patch are both green, $(63,21)$, as are the neon signs $(53)$, the gloomy walls of the hospital across the street from Nur's house, and the tiles darkening the walls inside the poet's house itself. There is also the dirty green handkerchief Murad uses while seeming to be playing another trick on the poor Deven, who turns quite grey with apprehension (30). Contrary to the film, which reminds the spectator that green has a positive significance for Islam by showing Nur's coffin covered with a green pall (while in the text, it is merely wrapped in white, the colour of mourning), the novel shows how Nur and his Muslim hangers-on contemptuously associate green with Hindu vegetarianism and cow worship: "But Hindi - oh Hindi is a field of greens"”, mocks one of Nur's disciples (54).

In this novel, where material and spiritual drought makes itself so intensely felt, blue appears very rarely and ironically. Far from offering relief, blue, like green, cruelly debunks its traditional iconicity. The dried-up fountain in Mirpore is painted blue, and so is the water cooler set up just before the University Board 
Meeting to impress, but which is destined to rust in the middle of a muddy puddle because it leaks. When blue is associated with writing, it serves to symbolize Deven's hopes and aspirations, but these are, of course, always dashed. For example, it is on blue paper that Deven's friend Abid Siddiqui has scrawled a few words in Urdu to tell him that the University will pay for the tape-recorder he needs to interview Nur, raising Deven's wildest hopes of release from his narrow life: "Seeing that line waver and break up and come together again upon the sheet of blue paper, Deven felt as if he were seeing all the straight lines and cramped alphabet of his small tight life wavering and dissolving and making way for a wave of freshness, motion, even kinesis."(110) Similarly, the volume of Nur's poems Deven imagines "bound in sky-blue cover" and bearing the title inscribed in the poet's hand (177), will never be published. For the only writing on sheets of blue paper Deven receives at the end of the novel come from Imtiaz Begum: "The writing upon them was large, sloping, filled with flourishes and ornamentations. The words ran into each other like one wave upon another merging into a whole flood" (215). The image of the wave, repeated here, does not give Deven any sense of buoyancy, this time. Having given up on his dream of publishing Nur's poetry, he feels swamped by Imtiaz's offerings, so, ironically, her poems will end up on the dust-heap: "Sarla, coming in with her duster, looked at him tearing up a bundle of blue sheets of paper into strips, and cried, 'You're dropping rubbish all over the floor I have just swept!'” (217)

There are of course other colours in the novel, but their occurrences are less frequent and do not establish a pattern as the ones examined here do. Clearly, the way Anita Desai uses the primary colours as well as green in In Custody is very different not only from the way colours are dealt with in Merchant's film, but also in Desai's other novels. In Bye Bye Blackbird, for example, the colours can be rich, dazzling, sensual, whereas here they are worked into the texture of greyness only to reinforce a sense of horrified nausea. For example, in the following passage, the colours lighting up the evening sky above Delhi form a picture which bears little resemblance with the more conventional, seductively exotic depictions of India in Technicolor:

The white-hot sky became blotched with the city's soot and faded to grey and then to mauve and finally to an uneasy, disturbed darkness. It could not become wholly dark because then the shops and cinema houses and restaurants and streets of the bazaar below lit up for the night and the sky was tinged sporadically red and orange and yellow and violet, like an old hag at a fair crazily dancing a dance of seven veils. (IC 46)

Clearly, in this passage, what makes colour in this novel appear so horrible is the fact that it monstrously enhances a deathly, decaying body. Colour is not even deceptively beautiful; its very garishness unambiguously advertises the corrupt nature of the underlying reality. In her book, Marta Dvorak has conclusively shown how the nightmarish qualities of the novel stem from Desai's adhesion 
to the katabatic dynamics of romance as analysed by Northrop Frye. One may wonder at the obsessive sense of repulsion, which so affects colours in this novel. Where does it come from, what motivates it? Deven himself, of course, is fastidiously disgusted by the world around him, not only intellectually, spiritually and morally, but also physically: he feels contempt for his ugly, despondent, embittered wife, his badly educated son, his illiterate in-laws, his vulgar colleagues, the friendly but overbearing shopkeeper on the bus, etc; he finds Nur's greedy eating habits, Siddiqui's sexual preferences and Imtiaz's former profession (and even her literary ambitions) morally repulsive; he is also in constant fear of dirt and germs and typically rejects food or drink, no matter how kind the offer. To a certain extent, therefore, the main protagonist's outlook on life does unflatteringly colour the world described. However, his point of view is never contradicted or even qualified by the narrator, so that one is justified in reading into this general obsession with filth and contamination the expression of a cultural specificity linked with religious, and more specifically, Hindu taboos. Western scholars such as Luc de Heuch have tended to find the obsession with the purity/pollution binary which is crucial to Hindu cosmology to be exotic and even puzzling. De Heuch even deems it a tragedy of Indian culture that it should be founded on the metaphorical extension of nausea, as he sees it, and deplores the fact that the metaphorical obsession with pollution should regulate thought, prohibitions and classifications.

A problem with such an interpretation in the case of In Custody, however, is that the novel clearly asserts the need for cultural and political desegregation, which goes against the exclusively religious interpretation. Indeed, according to his name, Deven Sharma is a Brahmin. Yet he does not practise any particular rites, although his wife Sarla regularly gives offerings to Lakshmi, the goddess of Luck (155). He even eats meat, and teaches in the Hindi department although Urdu is his mother tongue and Urdu poetry his only passion. Moreover, religious fanaticism is explicitly denounced, as in the passage in which a neighbour Deven particularly dislikes is described as having a face both "sanctimonious and martial, like a hatchet in the hands of a fanatic." (65) It is arguably possible, therefore, to dissociate In Custody from the fateful imagination of pollution, and see it as being neither specifically religious nor even specifically "Indian" in the sense de Heusch means. Instead, keeping in mind the parallel the novel establishes between the obsession with dirt (be it dust, mould or refuse) and existential despair, it might be illuminating to compare Desai's work with other examples of postcolonial fiction. One novel, for example, springs to mind: The Beautyful Ones Are Not Yet Born (1968) by the Ghanaian writer Ayi Kwei Armah, like In Custody was also written in English and evokes "the pain of hope perennially doomed to disappointment" (Armah 12). The action of the novel takes place towards the end of Nkrumah's regime at a time when corruption and bad government had disappointed the high hopes placed in this emblematic figure. At the beginning of the novel, a striking description of a wooden rail smeared with different strata 
of dirt, paint and varnish, calls up a vision of perpetual conflict with decay as its only possible outcome:

What had been going on there and was going on now and would go on and on through all the years ahead was a species of war carried on in the silence of long ages, a struggle in which only the keen, uncanny eyes and ears of lunatic seers could detect the deceiving, easy breathing of the strugglers. [...] But of course in the end it was rot which imprisoned everything in its effortless embrace. It did not have to fight. Being was enough. In the natural course of things it would always take the newness of the different kinds of polish [...], and it would convert all to victorious filth, awaiting yet more polish again and again and again. (Armah 12)

Thematically, this description strangely echoes the long passage in Desai's novel portraying the slums around the bus station of Mirpore:

Those shacks of tin and rags, however precarious and impermanent they looked, must have existed always, repetitively and in succeeding generations, but never fundamentally changing and in that sense enduring. The roads that ran between their crooked rows had been periodically laid with tar but the dust beneath was always present, always perceptible. In fact, it managed to escape from under the asphalt and to rise and spread through the town, summer and winter, a constant presence, thick enough to be seen and felt. (12)

Both passages highlight the a-historical nature of the kind of struggle that excludes any possibility of direction and progress. In both novels, the human and social matter mindlessly perseveres in the type of self-replication that is an equivalent of stagnation and even, paradoxically, of death. I would argue, therefore, that it is relevant to interpret the obsessive concern with filth and refuse in In Custody in terms of the ideological, political and cultural nausea of some of the more Westernized postcolonial writers whose hopes and expectations for their nation after decolonisation were disappointed.

However, In Custody is not as radically and aggressively pessimistic as Armah's novel, and perhaps a reason for this might be found, paradoxically, in the rather weak, sensitive nature of Deven, who is easily made to feel guilty or insecure and who, in a sense, corresponds to the feminine stereotype (after all, Rushdie does call him a "wimp", Rushdie xix). The choice of a character who has such difficulty in asserting himself in spite of his aspirations seems to reflect Desai's personal experience: she has spoken in interviews of the difficulty in reconciling the roles of the traditionally devoted wife and mother with that of the writer driven by personal ambitions. At the end of this novel, as in Clear Light of Day, the main character agrees to sacrifice these personal ambitions out of love for dependent figures (a retarded brother in Bim's case, a dying poet in Deven's). Both exchange a heroic "masculine" destiny for a greyer, more ancillary existence, the trick being to convince oneself that the terms of this alternative are somehow equivalent: "This alliance could be considered an unendurable burden - or else a shining honour. Both demanded an equal strength." (225). But because Deven is, in spite 
of everything, a man, it seems that the ending of In Custody must borrow from the imagery of the Passion of Christ, which presents self-sacrifice as heroic by stressing the violence contained in one's eager surrender to suffering. In the last scene of the novel, grey is mentioned, but only as a transition this time, between the blackness of despair and the whiteness of a spiritual awakening: "The sky was filling with a grey light that was dissolving the dense blackness of night. It glistened upon a field of white pampas grass which waved in a sudden breeze that had sprung up, laughing, waving and rustling through the grasses with a live, rippling sound" (224).

Yet it is difficult to find this ending fully convincing, because of the rather clichéd nature of the allusions to the divine breath quickening the world, to the calamities flashing from the sky like swords to cut Deven down, and to the branch of thorns which does not long impede his inspired progress back to a life of crushing responsibilities. Besides, to "believe" unconditionally in this ending would mean that religion (and Christianity at that!) could be reintroduced as a valid answer to all the character's existential angst. This would be politically disturbing indeed, considering the way Desai tries to present Hinduism and Islam as the two religions of India which were united in the common heritage of the Urdu poetic tradition. I would like to argue that the ambivalence of the last scene sends us back to a former one in which black and white are also present but, this time, in a non-figurative, and to a certain extent, non-religious mystical context. This passage, situated a dozen pages before the end of the novel, relates an incident which occurs at a moment when Deven is ruined, both financially and professionally, and finds himself let down by those he thought were his friends. The heat, which has been building up since the beginning of the novel, is particularly intense the afternoon Deven walks around in a daze through Old Delhi, from Chandni Chowk bazaar, past the Red Fort, to what is recognizably the Friday Mosque. It is at the end of this aimless tour of the part of Delhi which owes most to Shah Jahan, that Deven is granted a glimpse of the inexpressible truth contained in the poetry of old Nur Shahjehanabadi. The fact that the poet's surname happens to mean "of the city of Shah Jahan", or more fully, "the city of the Ruler of the World" invites us to establish a parallel between the forgotten poet's grotesquely decrepit state and the city's, perhaps suggesting that the city has been made to resemble the "old hag" dancing seductively at a fair since the Partition, which has banished from the city its own past glory and has abandoned it to a trashy, commercial subculture.

Significantly, it is in a small park where "all was calmly geometrical" that Deven experiences a moment of detachment and peace while gazing over the rooftops of the city at the main entrance of the great mosque:

The sun was behind it, in a great brassy conflagration, dazzling his eyes, but its forms and lines stood out against the heat and light clearly. The white and black marble facing of the eastern doorway made a graceful calligraphic pattern. The enormous arched doorway soared upwards to the dome which rose like a vast 
bubble that the flat earth had sent out into the dusty yellow-grey sky, a silent exhalation of stone. It was absolutely still, very serene. It was in fact the silent answer to his questioning. (211)

The silent and inexpressible eloquence of the geometric abstraction and of the calligraphic pattern gives to the contrast between black and white a very different meaning from the one in the final scene. Here the contrast does not oppose black and white, but rather balances them harmoniously. Besides, since the calligraphic inscription is taken out of its textual dimension, it cannot be interpreted in a purely religious way, but the aesthetic pleasure afforded by the black and white pattern can be seen as leading up to the contemplation of a transcendental absolute. The pattern gracefully embellishes the gigantic architectural shape so as to promote a kind of revelation, which is devoid of any violence, since it is a serene meditation on quintessential form: "Gradually the sky disappeared, the sun and the light and the glare, and the shape became clearer and sharper till it was all there was - cool, high-minded and remote" (211). This contemplation of a purely formal, abstract absolute enables Deven to distance himself for the first time from his surroundings and his personal aspirations, needs and fears. When the colours and sounds of the city reassert themselves around him after this moment of mystical detachment, he is able to comprehend the non-scientific, non-utilitarian specificity of poetic and artistic perfection:

If art, if poetry, could be made to submit their answers, not merely contain them within perfect, unblemished shapes but to release them and make them available, then - he thought, then -

But then the bubble would be breached and burst, and it would no longer be perfect. And if it were not perfect, and constant, then it would all have been for nothing, it would be nothing. (212).

Focussing as it does on calligraphy and geometry, this passage arguably reveals Desai's temptation with pure form, which is confirmed by the fact that she has admitted being increasingly interested in poetry, and in the way poems "use language": "I would like to achieve that gravity, compression, the intensity of their language," she told Magda Costa in 2001. However, her dedication to the brand of uncompromising realism she defines her own work by probably made it impossible to conclude on this vision of detached harmony, at the end of chapter 10. Indeed, the novel makes it clear that the artist and the art-lover must be committed to militant realism, for in India, the legacy of the high tradition of Urdu poetry which constitutes one of the nation's cultural treasures is really threatened. This is what chapter 11 highlights by showing us the destruction of the haveli Siddiqui inherited from a nawab ancestor, and by evoking the horrible death of Nur's pigeons, the emblems of his poetic inspiration: they are slowly suffocated by a "grey mold that grows till it caps the bird's head, closes its eyes and seals its beak" (221). 
Although Desai is famous throughout the world, she has received none of the more prestigious Western prizes, even if three of her novels were short-listed for the Man Booker Prize. Certainly the short format, the rather stifling atmosphere and the pessimistic vision of her novels and short-stories go against the trend set by Salman Rushdie's baroque, gargantuan, profuse and colourful works. It may be that his aesthetics better fit the way India and Indian art were defined in the West, back in the $19^{\text {th }}$ century. On the authority of the findings of the Eastern Culture specialists of his day, didn't Hegel, in his Aesthetics, define the Indian epic as a kind of shapeless, many-headed monster? Even today, it would appear that the expectations of a Western audience are still, to a certain extent, influenced by orientalist stereotypes, at least if we go by this somewhat condescending comment on the film adaptation of Desai's novel: "Merchant's film has a mood, a texture, and composition that is disarmingly vital and colourful, blending the many sights, sounds, and traditions of India into one great untidy whole" (Spring). The critic resuscitates the clichéd allusion to the irrational attraction of the East by referring to its disarming vitality, and to its vibrant, messy profusion. That this should be an insightful description of the film is debatable, but it is definitely completely at odds with Desai's work, which, if anything, is closer to the poetic economy of classicism. More relevantly, I believe, it is possible to say that In Custody bears the mark of an exacting art of writing that refuses to resolve comfortably the tension between, on the one hand, a politically-orientated approach of colour, and on the other, a detached fascination for essential form.

Anne LE GUELLEC

Université de Bretagne Occidentale

\section{Works Cited}

Armah, Ayi Kwei. The Beautyful Ones Are Not Yet Born, Oxford: Heineman, 1988.

Costa, Magda. "Interview with Anita Desai", 30 Jan 2001, http ://www.sawnet.org/ books/writing/desai-interview.html.

de Heusch Luc. Preface to Mary Douglas, De la Souillure, Paris: François Maspero, 1981.

Desal, Anita. In Custody, London: Vintage, Random House, 1999.

Dvorak, Marta. The Faces of Carnival in Anita Desais' In Custody, Paris: PUF, 2008.

Khan, Nyla Ali. "Places and Politics of Identity in Anita Desai's In Custody", The Atlantic Review, Vol 5, n 1-2, Jan-March \& Apr-Jun, 2004: 128-145.

MeEr, Amena. "Interview of Ismail Merchant", Brant Publications, Inc, 1994, http:// www.highbeam.com.

Rushdie, Salman. Preface to The Vintage Book of Indian Writing 1947-1997, Salman Rushdie, Elizabeth West, eds., London: Vintage, Random House, 1997.

Spring, Justin. "One for all", Artforum, 01/02/2006, http://www.highbeam.com. 